This is a post-peer-review, pre-copyedit version of an article published in Diplaris S., Satsiou A., Følstad A., Vafopoulos M., Vilarinho T. (eds) Internet Science. INSCI 2017. Lecture Notes in Computer Science, vol 10750. Springer, Cham, pp. 7-20. The final authenticated version is available online at: http://dx.doi.org/10.1007/978-3-319-77547-0 1

\title{
On the Educational Curriculum in Finance and Technology
}

\author{
Tatja Karkkainen \\ Adam Smith Business School \\ University of Glasgow \\ t.karkkainen.1@ research.gla.ac.uk
}

\section{Daniel Broby}

University of Strathclyde

Accounting and Finance

daniel.broby@strath.ac.uk

\author{
Georgios A. Panos*, 1 \\ Adam Smith Business School \\ University of Glasgow \\ georgios.panos@glasgow.ac.uk
}

\author{
Andrea Bracciali ${ }^{2}$ \\ Computing Science and Mathematics \\ University of Stirling \\ abb@cs.stir.ac.uk
}

$1^{\text {st }}$ October 2017

\begin{abstract}
Recent technological developments have enabled a wide array of new applications in financial markets, e.g. big data, cloud computing, artificial intelligence, blockchain, cryptocurrencies, peer-to-peer lending, crowdfunding, and robo-advising, inter alia. While traditionally comprising of computer programs and other technology used to support or enable banking and financial services, the new fintech sector is often seen as enabling transformation of the financial industry. A more moderate and critical view suggests that for the full transformative potential of fintech to be enabled, there is a need for an updated educational curriculum that balances knowledge and understanding of finance and technology. A curriculum that provides a skill portfolio in the two core components and complements them with applied knowledge can support the enabling forces which will render fintech as a true opportunity for the financial service industry and for society as a whole. We attempt a scholarship inquiry into the educational curriculum in finance and technology, aiming to inform this modern educational agenda. We review skills shortages, as identified by firms and experts, and examine the state-of-the art by some of the first educational programs in fintech.
\end{abstract}

Keywords: $\quad$ Finance, Financial technology, Fintech, Educational curriculum

JEL Classification: A12, A13, A22, A23, G41, I22, O32.

₹ All authors have benefited from participation and knowledge exchange taking place as part of the Scottish Business School Forum.

* Corresponding Author: Accounting and Finance, Adam Smith Business School: University of Glasgow, Gilbert Scott building, Room 545A Glasgow G12 8QQ, United Kingdom. Telephone: +44(0)141 330 5317, Fax: +44(0)141 3304939, e-mail: Georgios.Panos@ glasgow.ac.uk.

1 Panos gratefully acknowledges funding from the PROFIT project. Project PROFIT has received funding from the European Union's Horizon 2020 Framework Programme for Research and Innovation under grant agreement no. 687895

2 Bracciali based his contribution to the paper upon work from COST Action IC1406 cHiPSET, supported by COST (European Cooperation in Science and Technology). 


\section{Introduction}

Fintech can be perceived to be an amalgamation of finance and innovative information technology, which can make services and operations more efficient, less costly and enable the provision of new products and services. While traditionally comprising of computer programs and other technology used to support or enable banking and financial services, the new fintech sector is often seen as entailing disruptive potential to the financial industry and markets. At the same time, employers and experts have identified notable skills gaps to the training and experience of graduates and employees who are likely to be employed in fintech occupations. Such shortages exist for graduates stemming from both the social sciences, such as finance and business, and the computer science background. The advent of new technologies is changing the skills required by the financial service industry. Importantly, what seems to be missing is the synthesis of balanced and applied programmes, combining multi-disciplinary skills and enabling graduates to cover the gap

Business schools are the first natural candidates to undertake the delivery of new fintech methods and respond to market needs. Financial institutions and large international corporations appear keen to engage with educational institutions in identifying market requirements and the desirable skills. It is vital that the new skill requirements are planned to be facilitated via an integrated delivery mode, entailing the essential technical skills in e.g. programming, data management and the development of applications, alongside a solid understanding of the foundations of finance, regulation and ethics. It is indicative that the CFA Institute is suggested to plan to introduce Fintech as a self-alone-standing unit in its 2019 curriculum (Butcher, 2017). While there are already elements of fintech included in its sections covering trading, private wealth and quantitative methods, the fintech additions are supported by the views of charter-holder practitioners in the industry (Chartered Financial Analyst (CFA) Institute, 2017).

In this position paper, we discuss skill gaps in the financial service industry and assess the current state of the art in fintech in academia. We also engage in a scholarship inquiry that attempts to identify the relevant elements of a curriculum that might aim to minimize the skill shortage reported by employers. We attempt a primary synthesis from the educational curricula in the two distinct disciplines that need convergence as a result of the "distributed" nature of the internet and the opportunities this might enable for the delivery of financial services. This first inquiry into an interdisciplinary curriculum is by no means exhaustive. Instead, it is 
intended as an invitation for further scholarship inquiry into academia and knowledge exchange with the experts in finance and information \& communications technology (hereafter ICT).

Section 2 assesses the potential skills gap in fintech, by presenting and reviewing the relevant managerial and academic viewpoints, and offering some insights from the literature on the skill portfolio. Section 3 assesses the potential for a new educational curriculum in finance and technology, by reviewing the current state of the art in terms of new programmes, and presenting the candidate elements of a synthesis in an interdisciplinary curriculum. Section 4 presents some critical concluding remarks.

\section{Fintech and the related skills gap}

The fintech domains that seem to entail the greater potential for groundbreaking applications involve: (a) Banking (Consumer \& commercial banking, Consumer lending, Business lending), (b) Payments (Point of sale payments, Payments backend \& infrastructure, International money transfer, Consumer payments), (c) Investing (Institutional investing, Equity financing, Retail investing, Crowdfunding), and (d) Infrastructure (Banking infrastructure, Small \& medium business tools, Financial transaction security, Financial research and data (Harris, 2017). Personal finance and financial awareness is another domain to which fintech applications can exert an impact. The financial service industry is a leading user of information technology and these technological developments change the market demand for skills (Bresnahan, et al., 2002).

When the above fintech product areas are considered, the development of related applications requires technical skills, from statistical analysis and data management to software coding skills, inter alia. Fintech is a field that can benefit from the development of multidisciplinary skills. For example, a designer of robo-advisor that services a large number of private wealth clients would not only benefit from asset allocation experience but also from skills to design artificial intelligence tools. He/she would also benefit from a solid knowledge of financial regulation and ethics. The review in World Economic Forum (2016) highlights that internet, cloud and big data technologies are the most likely candidates to drive change in the financial services. According to PricewaterhouseCoopers (2017) there is already a skill shortage in the areas of data analytics and artificial-intelligence innovation. A graduate that 
holds financial and ICT skills in the skill portfolio would have an advantage in this evolving labour market. It is evident that the financial-service industry is in competition with other industries for the acquisition and further development of related talent. The prediction is that, by 2020 , there will be a 9,000,000 skill shortfall in related jobs in Europe (Cedefop. 2015). Apart from the growth in the business and finance vacancies, driven by emerging financialservice models, there is also increasing need for employees with related management skills (World Economic Forum, 2016), e.g. on managing innovation.

When more generic ICT jobs are considered, there is already a lack of high technical skills, which is deemed only to deepen. The Institution of Engineering and Technology Skills and Demand in Industry (2016) confirmed the strong demand for skilled employees in science, technology, engineering, and mathematics (STEM) disciplines. Among organisations hiring in STEM roles, 59\% reported lack of practical skills, and $43 \%$ mentioned the lack of work experience. There is a widespread agreement amongst the respondents regarding a more balanced and applied skill portfolio, as $91 \%$ stated that a better integration between work placements and academic studies would help. 50\% of the surveyed representatives reported substantial, and increasing skill gaps amongst their recruits. The skills of recent graduates represent a major challenge, as stated by $62 \%$ of the respondents. In close proximity to STEM occupations, the fintech sector sees similar challenges. It is also the case that the skill shortfall might be even more starking, due to the novelty of the techniques involved, and the seeming lack of a multidisciplinary skill portfolio among the graduates the fintech sector might be seeking for.

On the demand side, in managerial interviews from the European Company Survey in Eurofound (2015), finance was the industry, in which companies perceived to have the least difficulties in hiring staff. However, the same report stated that by the year 2020 there will be a shortage of ICT personnel in Europe and the technological advancement is also contributing to the skill mismatch across industries. The specialist knowledge, especially when involving synthesis of ICT and finance, seems to be an area that has a skill gap. According to PricewaterhouseCoopers (2017), the financial-service industry is in rising demand for advanced data analytics skills and knowledge. $72 \%$ of the interviewed financial service CEOs were concerned about the skill portfolios of job applicants and $73 \%$ of them were concerned about the speed of technological change. Both figures were higher, compared to surveys of previous years. 
While CEOs were looking to employ more people in asset and wealth management, it is the case that in the fields of insurance, banking and capital markets CEOs were prioritizing on skills pertaining to digitalization and technology. Moreover, $83 \%$ of the insurance CEOs responded they had anxiety for the speed of technological change and $81 \%$ of them had similar feelings toward skills shortages. These figures were increased, compared to figures close to $70 \%$ in the previous year. For insurance company CEOs, the development of artificial intelligence is a challenge, but also an opportunity, particularly if it facilitates the current practices.

CFA Institute (2017) surveyed how charter-holder members perceived the near-future impactful trends. Big data was thought to have a moderate to significant impact on financial analysis by $81 \%$ of respondents, the use of robo-advisors in private wealth had the support of $67 \%$ respondents, and the view that investment managers should benefit by having fintech skills received support by $68 \%$ of respondents. Financial analysis, big data analytics, artificial intelligence, machine learning and algorithmic trading are all said to be incorporated into the CFA exam curriculum from 2019 onwards.

On the demand side, the empirical evidence on the consensus regarding the need for new interdisciplinary skills and related training appears solid. The European Skills and Jobs Survey by Cedefop (2015: p.75) examines the share of jobs with significant rise in the need to learn new things by industry in the European Union (hereafter EU). The survey results indicate that the financial insurance and real estate services are the second highest among 16 industries. The ICT industry is at the middle of the distribution among industries, but still scores relatively high. However, using the same survey, Pouliakas (2016) finds that the top 5 occupational groups with rapidly changing skill profiles are ICT professionals and associate professionals, production or specialist service managers, health professionals, electronic and electronic trade workers/science and engineering professionals. Documenting the share of EU jobs with accelerating task complexity, Cedefop (2015: p. 18) shows that financial insurance and real estate services are at the top among 16 industries. $74 \%$ of the employees reported a change or increase in the variety of job tasks since they had started their jobs. Examining the drivers of change by industry, World Economic Forum (2016: p. 9) reports that for the financial service industry and the ICT industry, some of the most significant drivers of change were mobile internet and cloud technology, processing power and big data, consumer ethics and privacy issues, the internet of things, the sharing economy and crowdsourcing. Examining the incidence 
of work-based learning (hereafter WBL), Cedefop (2015: p. 16) documents that in finance, business and economics, as well as in other social sciences, some $30 \%$ of respondents had received WBL, with the figure in computing sciences being close to 39\%. Examining the source of WBL, Cedefop (2015: p. 64) documents that 60\% of professionals in ICT services received their training only within an education institution, with the figure being $67 \%$ for professionals in financial, insurance or real estate services. The figures for formal learning at the workplace were among the lowest for the two groups, at $30 \%$ and $31 \%$ respectively. The figures indicate the relevance and importance, as well as the challenge at hand, for academic institutions to undertake the training for the new fintech curriculum.

In the labour economics literature, a skills mismatch is a situation in which there is a discrepancy between the qualifications and skills that individuals possess and those needed by the labour market, i.e. a pillar of labour market mismatch (Cedefop, 2010). Employers are unable to find the right talent, despite offering competitive wages and, as a result, face skill shortages. Skill gaps arise where the skills required are unavailable in the workforce, for example, due to technological advance. Thus, with underskilling (or skill gap), individuals lack the skills and abilities necessary to perform the current job adequately (Cedefop, 2012; 2015). From this perspective, there does seem to be a fintech skill shortage in the financial industry, as the demand for particular skills exceeds the supply of those skills in the prevailing pay. This is confirmed by CEOs and industry representatives who mention there appears to be a skill deficit among current employees. The skills and abilities of candidates are lower than the new benchmark level of skills that technological innovation and new fintech applications and promises are setting.

More recent works in the skill-portfolio literature provide evidence for the importance of skills that are acquired via experience and can be applied to different settings (Panos, et al 2013). Human capital accumulates at the firm level through education, learning-by-doing and learning-by-interacting, but may also be acquired externally (Robinson, 2017). As shown by Shaw (1987), occupational change occurs when there is a positive difference between the present value of the current and an alternative occupational pathway. She illustrates that the degree of transferability of skills across occupations is an important determinant of occupational choice, with a higher degree of transferability being associated with a greater probability of individuals moving to another job. The return to investment in a particular skill is increasing in its subsequent rate of utilization, if investment costs are independent of how 
acquired skills are employed (Rosen, 1983). The skill-weights approach by Lazear (2009) assumes that all skills are general in nature, but the combination of single skills varies from firm to firm. Thus, specificity can be entailed in any type of occupational training, as only the combination of single skills makes them specific ${ }^{3}$.

Acemoglu and Autor (2011) emphasize that the trends in modern labour markets require the distinction between skills and tasks. A task is a unit of work activity that produces output, while a skill is a worker's endowment of capabilities for performing various tasks. The distinction becomes particularly relevant when workers of a given skill level can perform a variety of tasks and change the set of tasks that they perform in response to changes in labour market conditions and technology (Robinson, 2017). Acemoglu and Autor (2011) link the polarization of employment to the 'routinization' hypothesis and explore detailed changes in occupational structure across the US and OECD in light of that framework. Routine tasks are characteristic of many middle-skilled cognitive and routine jobs, such as book-keeping, clerical work and monitoring jobs. Technical advancement in this manner would complement either high skilled or low skilled personnel in their tasks. The supply of labour in the market, e.g. those who have completed their degrees, is deemed being in the "race" with the demand for skill emitting from the changes in the technology (Tinbergen, 1974). The traditional view on technological progress was that it especially affects the demand for roles that majorly consist of elements of routine tasks (Acemoglu and Autor, 2011). These are the middle-level skilled roles. However, when it comes to ICT in the fintech era, the transition that seems more relevant is that from routine cognitive (and even manual) skills to non-routine cognitive skills, involving primarily analytical, but sometimes even inter-personal, tasks (Aedo, et al., 2013). The design of fintech applications requires both an understanding of finance and high-level technical skills, e.g. in big-data management. These skills can be used to create artificial intelligence enhanced solutions, blockchain applications, cryptography - including smart contract - and financialservice applications on the internet. Such tasks are related to a broad spectrum of financial application, including how paying, investing, borrowing or receiving investment advice is conducted (He, et al., 2017).

\footnotetext{
${ }^{3}$ Following this approach in building occupation-specific skill-weights for Germany, Geel, et al. (2011) show that occupation-specific skill portfolios entail higher net costs of apprenticeship training and small occupational change probabilities.
} 
Considering the above background and assessments, it appears that when it comes to the fintech curriculum, the skill-portfolio approach provides a suitable framework of study. Both managers and employees are aware of the need for new skills and seem to identify the increasing skills gap. Under that prism, it might thus be the case that work-based learning and an occupation-specific fintech skills learning approach is not the most efficient for either the worker or the firm. Thus, the scope of an updated business school fintech curriculum is a most important modern endeavor.

\section{An educational curriculum for a fintech-skills portfolio}

Given the ongoing development of corporate fintech activity, one can easily infer that a solid relationship between academia and the industry for the training of the next generation of fintech graduates is in order. This collaboration will aim for enhanced graduate employability, skill transferability and - importantly - the informed development of fintech applications in directions that are compatible with ethics, regulation and the pivotal targets of client protection and social performance. The latter two are the pillars of responsible banking and finance, a model that aims for the enhancement of financial capability and societal well-being. It is worth remarking the positive role that commercial funders as well as governmental agencies can play to support a better integration between the educational curriculum of universities and training providers and the aims of the financial service industry. Hence, catering to the identified skills gap can and should be seen as an opportunity for rendering fintech development as conducive to the enhancement of financial capability and societal well-being.

Due to the very recent development of the field, the skills pertaining to the fintech sector have not yet been organised in a widely-recognised supporting body of knowledge to be used by taught programmes. The natural first step in the development of academic fintech programmes pertains to efforts for the integration of the distinctive disciplines into comprehensive applied programmes. This development can again be seen as an opportunity to enhance the domains of interdisciplinarity, industry-relevance, knowledge exchange, and social impact by the academic programmes of business schools. A large number of existing non-fintech programmes stems from a single background, i.e. ICT, engineering, finance, accounting, business, economics, management or law. The finance and business curriculum is largely unknown in ICT disciplines and an integrated ICT curriculum is largely absent or 
limited in most finance programmes and business schools. We argue that the approach needed is a synthesis of the educational curriculum in finance and ICT, bringing the two strands together in a more cohesive way. This involves a greater emphasis by business schools on the planning, integration and delivery of courses related to data processing and analytics, programming languages, along with new elements regarding the digital transfer of value, such as blockchain and distributed ledger technologies. Hence, this synthesis of a curriculum must rely on multidisciplinary collaboration between academic experts.

According to Ernst \& Young (2016), businesses that are involved in fintech would benefit from sourcing skills within the fields of finance, technology and entrepreneurship. A single graduate would not need to possess them all in the skill portfolio, but the richness of a skill portfolio would certainly benefit the individual in this evolving labour market. When looking at the limited existing curriculum offering on fintech, a lot of the current emphasis is on describing fintech as a phenomenon, rather than involving the 'hard' core of skills needed in the two domains of finance/business and ICT. In this regard, and noting the scarcity of formal work-based learning and vocational training in the relevant sectors, the primary fintech skills would be better attained via university education.

The business schools are natural learning platforms of fintech due to their expertise in approaching business organisation problems from a multidisciplinary perspective. The curriculum would further benefit from designing the interdisciplinary courses to be more integrated rather than teach them in a 'silo' approach (Smith-Ducoffe, et al., 2006). Navarro (2008) makes a further claim that knowledge and teaching would need to be decompartmentalized. Given the task at hand, it is likely that curriculum development might benefit from some experimentation and case studies, involving e.g. the matching of academic pairs from the two primary backgrounds in the delivery of a new applied course that combines finance and its relevant technological applications. Learning can also be advanced through experiential methods, particularly in ICT ( $\mathrm{Li}$, et al., 2007), and in collaboration with the industry when it comes to graduate internships and work placements. Li, et al. (2007) also note that business schools have not generally been effective in teaching information systems.

From a management science perspective, a lot of the emphasis of business schools has been on describing the management of innovation or creativity. This expertise renders a natural candidate curriculum that can adapt to the management of the new digital assets, fintech processes and applications. In support of this argument, Fichman, et al. (2014) discuss the need 
for business students to understand how technology changes businesses or enables process and product innovation. Thus, stemming from the legacy of a number of successful Technology Management programmes, e.g. those of NYU, Columbia, Berkeley, University of California at Santa Cruz, University of Texas at Dallas, LSE, University of St. Andrews, ETH Zurich, and Technische Universität of München, the first two identified components of a modern fintech offering are redesigned courses on (a) Financial Information Systems and (b) Managing Innovation, along with any relevant variants.

An inquiry into the recently developed programmes on fintech reveals a tendency to move fast, in response to industry trends. It is vital that a list of well-defined industry/user requirements is obtained prior to the creation of courses. However, given the uncertainty of any innovation process, it is also the case that such a list is difficult to obtain in a concise manner. Certain programmes have been more innovative than other in their design and very few have emphasized on the essential 'hard' skills in technology. For instance, the MBA programme by NYU's Stern School of Business offers graduate courses in ICT training catering to certain 'hard' skills on e.g. programming and big data analytics. This is also the case with the MSc Fintech programme by the University of Strathclyde, which is probably the first of its kind in the United Kingdom and Europe. Some other new graduate courses on fintech seem to largely rely on the management-of-technology component. Wharton and Columbia provide fintech courses as a part of the MBA. MIT provided an online Fintech overview programme run on the Getsmarter educational platform, which was later discontinued. This online programme was focusing on new business model entrepreneurship. The Oxford University Saïd Business School also launched an intermediate fintech programme on the Getsmarter platform in Autumn 2017. The course is an overview of the fintech landscape and the possible applications that can stem from this new landscape. Edinburgh Napier University also provides an intermediate programme on describing the fintech solutions and the market place.

Our own inquiry into the components of the newly established programmes, and some further insights stemming from discussions with representatives of the financial industry suggest a 'hard' skill component in finance, comprising of the following six courses, and related adaptations: (c) Investment Portfolio Analysis/Management, (d) Financial Risk Management, (e) Applied Computational/Quantitative Finance, (f) Financial Regulation and Ethics, (g) Fintech Entrepreneurial Finance, (h) Fintech Personal Finance and 
Financial Planning/Wealth Management. The computational finance component can be thought to place emphasis on fintech applications and systematic trading. The fintech elements of entrepreneurial financial and personal finance are again related to an extensive redesigning of the traditional courses, enabling the incorporation of applications related to e.g. crowdfunding and $\mathrm{P} 2 \mathrm{P}$ lending ${ }^{4}$, robo-advising, etc. Other elements that can be considered as of high relevance to fintech applications are monetary economics, international finance, and development finance. However, these elements do not appear in any current offering.

Following a similar review process regarding the ICT component of fintech programmes, and noting the current limited current offering, we identify the following seven ICT elements, along with their variants: (i) Big Data:Systems/ Programming/Management/Analytics, (j) Artificial Intelligence, (k) Machine Learning, (l) Cryptography/Cyber-Security \& Forensics, (m) Human-Computer Interaction and Design, (n) Computer Visualization Methods and Applications, and (o) Blockchain Technology.

Some of the above components are worth further elaboration. An element that is novel and largely non-existent in the curriculum is that of blockchain technologies. Blockchain is considered to be a general-purpose technology, alongside facilitating innovation in electricity supply and the internet, which entails vast potential applications (Catalini and Gans, 2017). Specifically, in financial services, blockchain technology can be used for instantaneous trading and settlement, payments and transfers, and ultimately for record keeping. Blockchain applications can also involve an adaptation of tokens or cryptocurrencies, which are privately issued value-storing methods of exchange over the internet. The blockchain applications are considered as potentially conducive to cost reduction, the efficiency and security in transactions of all sorts. Because of the underlying technology, blockchain sees potential enabling applications beyond finance in areas such as supply chain and inventory management, the creation of national databases on e.g. citizen identification and land registry, and a fraud-proof authentication process for luxury items. In finance research, it is seen as relevant to corporate governance, e.g. in trading corporate securities on the blockchain, central banks and digital

\footnotetext{
${ }^{4}$ Crowdfunding leverages on the internet in reaching out to a larger group of interested parties and enabling them to participate in a new venture with smaller sums of money, either as investors or as early buyers. This fundspooling technology is mostly used as a new business model, but also for charitable purposes. Moreover, peerto-peer lending platforms lend to businesses but also to households that require consumer credit or mortgages. These are a new form of intermediary, catering to borrowers over the internet, using algorithms for matching borrowers and lenders, along with associated risk-return profiles.
} 
currency, sovereign debt management, overseas development assistance, financial inclusion and banking.

The inherent complexity of the blockchain would require an interdisciplinary approach to its course delivery. It engages and involves elements as diverse as peer to peer networks, game theory and "crypto-economics", monetary economics, cryptography, cyber security and formal verification, as well as software engineering, programming and software development. Some schools have recently started to introduce blockchain technologies in their curriculum offerings, with a few business, finance, law and, computing departments being the first to offer related courses. As a collaborative effort between NYU's Law School and the Stern Business School, a course on Bitcoin and Cryptocurrencies was among the very first that started in 2014. It was followed by the more technical Bitcoin and Cryptocurrency Technologies course by the University of Princeton, which is also offered online on the massive online open course (hereafter MOOC) platform Coursera. This is also the case with the University of Stanford's course on Bitcoin Engineering. In Europe, few Universities offer blockchain-related courses and programmes, such as the MSc in Digital Currencies at the University of Nicosia, in Cyprus (also available on a MOOC platform), and the more recent undergraduate module on Blockchains and Distributed Ledgers at the University of Edinburgh.

Cryptography can be applied as a part of online software security, trading verification and privacy upholding (Böhme, et al., 2014). It is also widely used in the security protocols of blockchain applications. Software security and the subsequent trust that is likely to stem from this feature among users, is an important aspect of any online, or standard, financial service platform. Cryptography can also be applied in designing smart contracts, which are preprogrammed automated contracts through which anonymous peers over the network can transact with each other (Szabo, 1997).

Big Data solutions that can facilitate in enhancing credit analysis, or be applied to risk management can also be used for creating machine learning or artificial intelligence tools for asset management (PricewaterhouseCoopers, 2013). Managing Big Data tasks pertains to managing large databases or constantly changing online data, using advanced programming and statistical analysis (McAfee and Brynjolfsson, 2012). These were not available or unfeasible with standard technologies of the recent past (Constantinou and Kallinikos, 2015). Big data tools are facilitated by the internet and the subsequent surge of available data, but also by the declining price of computing power and data storage. Finally, artificial intelligence can 
ultimately power scalable financial tools due to its ability to replace expensive human cognitive power (Markus, 2015), or improve the available service or enable the creation of new services. One of these new services is robo-advising, in which artificial intelligence manages the investment portfolio, and can reduce the asset management service fees charged (Lam, 2016).

\section{Some critical concluding remarks}

The review of the previous section is likely to lead to the rhetorical question if the above elements and their related 'hard' skills can be incorporated into a 1-year graduate curriculum. Their mere numbering suggests some 2 generic components, 6 core finance elements, and some 7 ICT domains. Thus, it seems that the answer to the above question, along with the design and duration of fintech programmes, and the choice of emphasis on either the 'soft' or the 'hard' skills largely depends on the target student audience and their backgrounds. The finance and business graduates and ICT/engineering graduates have different skillsets and comparative advantages in learning. One can think of conversion graduate programmes emphasizing on either of the two core components and addressing either of the two student audiences. For instance, an ICT graduate who wishes to obtain a solid knowledge in finance and engage in relevant applications as part of a graduate thesis, would be suitable for a programme that requires advanced ICT knowledge as an entry requirement. This is also the case for a finance/business graduate with some standard ICT knowledge, who wishes to further develop their ICT skills in fintech applications. Thus, in the case of 1-year MSc programmes, the programme leader would need to conduct some careful market analysis regarding the target audience. Within this rationale, the design of some more advanced programmes of 2 years of duration, such as the MBA programme of NYU Stern Business School, could be regarded as pedagogically more suitable for fewer entry requirements.

Another dimension that could be evident from the above analysis is that the fintech development offers an opportunity for the generation of joint undergraduate programmes, stemming from an interdisciplinary collaboration between finance and ICT programmes, and their related academic departments. It is likely such joint programmes are already in place in some institutions. However, it is worth emphasizing that what is currently largely missing is the integration between the ICT and the finance curriculum. Another aspect that needs catering to is the enrichment of the joint curriculum with applied courses engaging in the modern fintech 
applications. A new fintech offering would require that the two related educational curricula adapt and evolve. Over time, we would expect a more well-defined body of knowledge to emerge.

A third element worth noting is that the endeavour to initiate new courses, based on either the 'hard' or the 'soft' fintech components, can be seen as a necessary first step by institutions. Institutions can benefit from own comparative advantage in specializing in courses, instead of a whole programme, and make independent offerings in terms of MOOCs and work-based learning programmes. Thus, even if an institution does not have an immediate comparative advantage in the 'hard' fintech components or a legacy of strong interdisciplinary collaboration between business and ICT studies, the initiation of some relevant courses on either the 'soft' or the 'hard' core of fintech could still be a worthy investment. This will also set the foundations for later recruitment, training of the future lecturers, and potential programme development.

In conclusion, rapid developments in technology have led to a number of new financial applications, business models and ways to utilize big data. There is a need for an updated curriculum which addresses the changing needs for skills in the financial services, as identified by employers, employees and professional bodies. Skill gaps are largely technical in nature, but often also involve the lack of economics intuition and the limited understanding of regulation and ethical concerns. Social science and law school graduates, respectively, are typically better trained for these latter capabilities.

Critical thinking should be a primary element in the new curriculum offering. There is also a need for intensified knowledge exchange and transfer between academia and the industry, in the form of initiating scholarship inquiries, sharing and research findings, and embarking on joint apprenticeship and training programmes in applied fintech. One must also note that published research of excellent quality is currently scarce in fintech, at least in non-specialist journals, e.g. in the list by the Association of Business Schools (hereafter ABS). For researchled teaching to eventually occur, it would need to be the case that the industry is willing to facilitate academic researchers with information and data, and that universities and related bodies are willing to encourage and invest in research and scholarship activity in fintech. This dimension should normally precede the initiation of fintech courses and programmes. Thus, it must not be neglected. We believe that initiating joint research agendas will inform the curriculum, 'train the trainers' and, ultimately help minimize skill mismatches. 
As a critical concluding remark for this position paper, one must remark a lesson from recent history. Financial engineering has been integral to the growth and success of mortgage finance, along with the generation of several relevant derivative and securities products. With mortgage flows being inherently complex and volatile, their management required sophisticated financial engineering because of complex embedded options. Securitization, liability management, derivative instruments, and insurance were the key related tools, which were largely assigned to 'financial engineers', a relatively new specialization that appeared some years back. Back at the time, and somewhat similarly to the fintech rapid development, few universities followed the market trends in establishing well-defined financial engineering curricula, in terms of programmes and courses. Very few had the expertise to do so effectively, but almost all business schools eventually started courses related to describing the products. Anecdotally, a large portion of the new employees in financial engineering occupations lacked the social science training, and potentially the sound understanding and intuition around societal dynamics, ethics and regulation. As followed, the mortgage crisis - and the much broader financial-crisis consequences - exposed issues with how far financial engineering had gone, with all its multiple layers, i.e. the mortgage loan, complex securitization in multiple levels, derivatives on the securities, and the new entities investing in the securities and derivatives. The history shows that risks increased at each step due to complexity, leverage, total size of the exposure relative to economy, but also often due to fraud and misrepresentation, and inflexibility to deal with change.

With the finance and business curriculum being largely unknown in ICT studies and the ICT curriculum being largely absent in finance, business and social science training, one should be able to see some similarity to the case of financial engineering training and related unintended practical outcomes. Economists understand well that modeling social dynamics is not a trivial exercise, both in terms of the theory and the applications. Behavioural economists can further adhere to the severe considerations involved when considering predictions, forecasts and expectations within social networks. When considering the design of processes or products that embed social interaction and can impact societal well-being, one must be aware of the related dynamics and potential limitations. Not all of these can be addressed by technology on its own or be embedded in a smart contract or be left to chance when customizing a process or service.

The development of technologies, such as the blockchain, is supposed to entail great potential to lead to more efficient outcomes, via bringing anonymity, trust in the underlying 
technology, transparency and several other desirable properties. However, for the technology and its applications to be developed in a way that enables efficient, welfare-enhancing, capability-enhancing and real economic and societal outcomes, the architects, engineers and developers of that technology would need to be trained via a modern integrated curriculum. That curriculum would need to be built on solid foundations, i.e. without mere rushing in following any short-term market trend. Furthermore, the recent history can not help emphasize enough that among the core skills of this curriculum should be critical thinking, business ethics, and understanding regulation and compliance. Such a skill portfolio would enable fintech applications founded upon strong technical skills, alongside the understanding of societal dynamics. If such applications are to come to fruition, then one can feel safe that fintech is a true opportunity for a much-needed positive disruption in practices, which can enhance financial capability and societal well-being. 


\section{References:}

Acemoglu, D. and Autor, D. (2011) Skills, tasks and technologies: Implications for employment and earnings. In The Handbook of Labor Economics (eds. Ashenfelter O. and D. Card), Elsevier, Vol. 4, Part B, Chapter 12, xciii-xcvi.

Aedo, C., Hentschel, J., Luque, J., and M. Moreno (2013). From occupations to embedded skills: A cross-country comparison. Background paper for the World Development Report 2013.

Bresnahan, T. Brynjolfsson, E. and Hitt. L (2002). Information technology, workplace organization and the demand for skilled labor: A firm-level evidence. Quarterly Journal of Economics 117, pp. 339-76.

Butcher, D. (2017). Fintech is about to become a big part of the CFA exams. This is what you should know. Efinancialcareers.

Catalini, C. and Gans, J.S. (2017). Some simple economics of the blockchain. Rotman School of Management Working Paper No. 2874598.

Cedefop (2010). Briefing note: Skill mismatch in Europe. June 2010.

Cedefop (2012). Skill mismatch: The role of the enterprise. Research paper no. 21.

Cedefop (2015). Skill shortages and gaps in European enterprises: striking a balance between vocational education and training and the labour market. Luxembourg: Publications Office. Cedefop reference series; No 102.

Cedefop (2015). Skills, qualifications and jobs in the EU: The making of a perfect match? Evidence from Cedefop's European skills and jobs survey. Cedefop reference series; No 103. Luxembourg: Publications Office.

Chartered Financial Analyst (CFA) Institute (2017), Practice Analysis Trends.

Constantinou, I.D. and Kallinikos, J., (2015). New games, new rules: big data and the changing context of strategy. Journal of Information Technology 30 (1), pp. 44-57.

Ernst \& Young. (2016). UK fintech on the cutting edge. Commissioned by HM Treasury.

Eurofound (2015), Third European Company Survey - Overview report: Workplace practices - Patterns, performance and well-being, Publications Office of the European Union, Luxembourg.

Fichman, R. G., Dos Santos, B., and Zheng, Z., (2014). Digital Innovation as a Fundamental and Powerful Concept in the Information Systems Curriculum. MIS Quarterly 38 (2), 329-343.

Geel, R., Mure, J. and U. Backes-Gellner (2011). Specificity of occupational training and occupational mobility: An empirical study based on Lazear's skill-weights approach. Education Economics. 19(5), 519-535.

Harris, M. (2017). The fintech revolution. The Alumni Magazine of NYU Stern School of Business. Spring 2016

He, D et al. (2017). Fintech and Financial Services: Initial Considerations. International Monetary Fund Staff Discussion Notes No. 17/05. 
The Institution of Engineering and Technology Skills and Demand in Industry (2016). Skills \& demand in industry: 2016 survey. Available at: http://www.theiet.org/factfiles/education/skills2016-page.cfm?type=pdf

Lam, J.W. (2016). Robo-advisers: A portfolio management perspective. Senior Thesis, Yale College.

Lazear, E.P. (2009). Firm-specific human capital: A skill-weights approach. Journal of Political Economy, 117(5), 914-940.

Li, T., Greenberg, B.A. and Nicholls, J.A.F. (2007). Teaching experiential learning: Adoption of an innovative course in an MBA marketing curriculum. Journal of Marketing Education, 29, 25-33.

McAfee, A. and Brynjolfsson, E. (2012) Big data: the management revolution. Harvard Business Review 90(10). 51-68

Markus, L. (2015) New games, new rules, new scoreboards: the potential consequences of big data. Journal of Information Technology, 30 (1), pp. 58-59,

Navarro, P. (2008) The MBA Core Curricula of Top-Ranked U.S. Business Schools: A Study in Failure? Academy of Management Learning and Education 7, 108-123.

Panos, G. A., Pouliakas, K. and Zangelidis A. (2013). Multiple job holding, skill diversification and mobility. Industrial Relations: A Journal of Economy and Society. 53 (2), 223-272

Pouliakas, K. (2016). What are the skills of the future? Skills panorama blog. $5^{\text {th }}$ Jul. 2016.

PricewaterhouseCoopers (2013). Where have you been all my life? How the financial services industry can unlock the value in Big Data. PwC FS Viewpoint.

PricewaterhouseCoopers (2017). Ahead of the curve: Confronting the big talent challenges in financial services. 20th CEO Survey.

Rosen, S. (1983). Specialization and human capital. Journal of Labor Economics. 1(1), 43-49.

Robinson, C. (2017). Occupational mobility, occupational distance and specific human capital. Journal of Human Resources. Forthcoming.

Smith-Ducoffe, S., Tromley, C. and Tucker, M. (2006). Interdisciplinary, team-taught, undergraduate business courses: The impact of integration. Journal of Management Education, 30(2): 276-294.

Szabo, N. (1997). Formalizing and securing relationships on public networks. First Monday. 2(9).

Tinbergen, J. (1974). Substitution of Graduate by Other Labour. Kyklos, 27 (2), 217-226.

World Economic Forum (2016). The Future of jobs: Employment, skills and workforce strategy for the fourth industrial revolution. Global Challenge Insight Report. 